\title{
Could platelet distribution width predict coronary collateral development in stable coronary artery disease?
}

\author{
(D) Isa Sincer, ${ }^{1}$ (i) Asli Kurtar Mansiroglu, ${ }^{1}$ (i) Emrah Erdal, ${ }^{1}$ (i) Mehmet Cosgun, ${ }^{1}$ (i) Gulali Aktas, ${ }^{2}$ \\ (iD) Yilmaz Gunes ${ }^{1}$ \\ ${ }^{1}$ Department of Cardiology, Abant Izzet Baysal University Faculty of Medicine Hospital, Bolu, Turkey \\ ${ }^{2}$ Department of Internal Medicine, Abant Izzet Baysal University Faculty of Medicine Hospital, Bolu, Turkey
}

\begin{abstract}
OBJECTIVE: We hypothesized that hemogram parameters should be related to the development of coronary collateral vessels. For this purpose, we aimed to compare platelet distribution width (PDW) and PDW to platelet ratio (PPR) in subjects with stable coronary artery disease having adequate or inadequate coronary collateral development.

METHODS: A total of 398 patients with stable angina pectoris undergoing coronary angiography were enrolled and divided on the basis of the development of coronary collateral (CCD) (inadequate CCD ( $n=267)$ and adequate CCD ( $n=131)$. Routine complete blood count and biochemical parameters were measured before coronary arteriography.

RESULTS: Mean PDW and PPR values of inadequate and adequate CCD groups were 17.5\% (10-23) and 12.4\% (9.8-22) \%, $\mathrm{p}<0.001$, respectively. In multivariate analysis, age ( $p=0.012,95 \%$ CI for OR: $0.958(0.933-0.983)$ and PDW ( $<<0.001,95 \%$ CI for OR: 1.432 (1.252-1.618) were found to be statistically significantly different inadequate CCD group compared to adequate CCD group. Receiver operating curve (ROC) analyses revealed that a PPR value greater than 0.057 had $76 \%$ sensitivity and $51 \%$ specificity and a PDW higher than $16.2 \%$ had $80 \%$ sensitivity and $66 \%$ specificity in predicting inadequate CCD.

CONCLUSION: The present study suggests that PDW and PPR may be associated with the degree of collateral development in chronic stable coronary artery disease (CAD).

Keywords: Coronary collateral development; platelet distribution width; platelet distribution width to platelet ratio; stable coronary artery disease.

Cite this article as: Sincer I, Kurtar Mansiroglu A, Erdal E, Cosgun M, Aktas G, Gunes Y. Could platelet distribution width predict coronary collateral development in stable coronary artery disease? North Clin Istanb 2020;7(2):112-117.
\end{abstract}

T he development of coronary collateral circulation is very important for bodily functions since it enhances the blood supply of ischemic myocardium [1]. Well-functioning collateral circulation is associated with the lower incidence of adverse outcomes in stable coronary disease [2-4]. The causal relationship between ischemia and collateral circulation development is uncertain [5]. Thus, predictors of coronary collateral development (CCD) receive the utmost interest in literature. Novel studies reported a significant association between hemogram parameters and cardiovascular events [6-8]. One of these parameters is platelet distribution width (PDW), which has been suggested as a marker of patency of saphenous grafts after coronary artery bypass operations [9]. Platelet activity is reflected by the platelet distribution width (PDW), which measures the variation in platelet size. PDW has been found to be more specific for platelet activation than the

Received: September 26, 2019 Accepted: December 10, 2019 Online: March 19, 2020

Correspondence: Dr. Isa SINCER. Abant Izzet Baysal Universitesi Hastanesi, Kardiyoloji Klinigi, Golkoy, 14200, Bolu, Turkey.

Tel: +90 3742534656 e-mail: isasincer@yahoo.com

(c) Copyright 2020 by Istanbul Provincial Directorate of Health - Available online at www.northclinist.com 
mean platelet volume (MPV) [10]. PDW has not been affected by platelet swelling [10]. Heterogeneity and size variation of the platelets determined by PDW and higher levels of PDW reflects the variation of circulating mature and immature thrombocytes in bloodstream abnormal thrombosis or heterogeneous demarcation of megakaryocytes [11] might be responsible for elevated PDW. A ratio of PDW to platelet higher than 0.07 has been suggested as an independent mortality marker in the pediatric intensive care unit population [12]. Thus, we hypothesized that hemogram parameters should be related to the development of coronary collateral vessels. For this purpose, we aimed to compare PDW and PDW to platelet ratio (PPR) in subjects with adequate and inadequate coronary collateral development in chronic stable coronary artery disease (CAD).

\section{MATERIALS AND METHODS}

Patients with stable CAD who underwent coronary angiography between November 2015 and April 2017 were enrolled in this study after obtaining institutional board approval (04.12.2017; number: 68246970-903.99). Ischemic findings and or angina pectoris on electrocardiography or stress test were present in stable angina pectoris patients. Of those, minimum $95 \%$ occlusion in at least one main epicardial vessel was included in this study. Exclusion criteria were as follows: idiopathic dilated or hypertrophic cardiomyopathy, history of acute coronary syndrome within six months, history of coronary artery stenting or bypass operation, congestive heart failure, severe valvular disease, systemic inflammatory diseases, moderate to severe renal failure, severe hepatic dysfunction, atrial fibrillation, malignancy, leukemia and thrombocytopenia.

The study population grouped into adequate CCD and inadequate CCD groups according to the angiography results. Demographic characteristics, laboratory data and coronary angiography findings of the participants were obtained from the computerized database and patient files of the institution. Age, gender, weight, body mass index, comorbidities, smoking history, medicines in use and laboratory data were recorded.

\section{Laboratory Data}

Before coronary angiography, venous blood samples were drawn. Serum lipids, creatinine, and glucose were measured by an automatic analyzer (Architect C8000, USA). Simultaneous optical and impedance measurements (Cell
Dyn 3700; Abbott Diagnostics, Lake Forest, Illinois, USA) were used in the determination of hemogram parameters and PDW. PDW to Platelet ratio (PPR) was calculated by the division of PDW by platelet count.

\section{Coronary Angiography Evaluation}

The route for coronary angiographies was the radial or femoral artery in the present study. By visual evaluation, patients with equal to or more than $95 \%$ narrowing were included. Rentrop classification was used in the grading of coronary collateral circulation [13]. According to this grading system, lack of filling in collateral vessels grouped as Grade 0, filling in side branches via collateral channels without visualization of the epicardial artery was graded as Grade 1, partial filling in the epicardial major coronary artery via collateral circulation is graded to Grade 2, and complete filling in the epicardial major coronary artery graded as Grade 3. Three cardiologists who were blinded to this study evaluated the results of the coronary angiographies. The CCD with the highest Rentrop grade was used for analysis in cases with the presence of multiple coronary collateral circulation. Inadequate CCD was defined as patients with Rentrop grades 0 and 1 , while adequate CCD was defined as patients with Rentrop grades 2 and 3 .

\section{Statistical Analysis}

Statistical analysis was conducted using SPSS software (SPSS 18.0 for Windows, IBM Co, Chicago, IL, USA). Distribution of the variables in study groups was analyzed by the Kolmogorov-Smirnov test. Normal distributed variables were compared by t-test and expressed as mean \pm standard deviation. Variables without normal distribution were compared with the Mann-Whitney U test and expressed as median (interquartile range). Chi-square test was used for comparison of nonparametric variables. Pearson correlation analyses were used to assess the correlations of MPV, PDW, PPR and age with Rentrop grade. Multivariate linear regression analyses were used to analyze the value of different baseline characteristics as independent predictors of inadequate CCD. A Receiver operating curve (ROC) analysis was performed to observe the sensitivity and specificity of PDW and PPR. A p-value lower than 0.05 was considered statistically significant.

\section{RESULTS}

The study population included 398 subjects; 267 in inadequate CCD and 131 in adequate CCD groups. Subjects in 
TABLE 1. General characteristics of the study groups

\begin{tabular}{lccc} 
Baseline characteristics & $\begin{array}{c}\text { Inadequate } \\
\text { CCD }(\mathrm{n}=267)\end{array}$ & $\begin{array}{c}\text { Adequate } \\
\text { CCD }(\mathrm{n}=131)\end{array}$ & $\mathrm{p}$ \\
\cline { 2 - 3 } & \multicolumn{2}{c}{ Median (Min.-Max.) } & \\
\hline Age (mean \pm SD) & & & \\
(years) & $62(34-84)$ & $67(39-88)$ & 0.01 \\
Body mass index & & & \\
(kg/m ${ }^{2}$ ) & $28(21-47)$ & $27(20-48)$ & 0.08 \\
Male/female & $179 / 88$ & $102 / 29$ & 0.45 \\
Hypertension & $166(62 \%)$ & $82(63 \%)$ & 0.93 \\
Smoking & $65(24 \%)$ & $44(33 \%)$ & 0.06 \\
Family history & $34(13 \%)$ & $11(8 \%)$ & 0.19 \\
Diabetes mellitus & $110(42 \%)$ & $50(38 \%)$ & 0.84 \\
Acetyl salicylate & $152(57 \%)$ & $72(55 \%)$ & 0.71 \\
Clopidogrel & $36(13 \%)$ & $15(11 \%)$ & 0.56 \\
Statin & $91(34 \%)$ & $36(27 \%)$ & 0.16 \\
Calcium channel blocker & $35(13 \%)$ & $21(17 \%)$ & 0.11 \\
ACE inhibitor & $63(24 \%)$ & $31(23 \%)$ & 0.98 \\
ARB & $72(27 \%)$ & $25(19 \%)$ & 0.08 \\
B-blocker & $120(45 \%)$ & $120(46 \%)$ & 0.76 \\
\hline
\end{tabular}

CCD: Coronary collateral development; ACE: Angiotensin-converting enzyme; ARB: Angiotensin receptor blocker; SD: Standard deviation.

adequate CCD were significantly older than the patients in the inadequate CCD group [67 (39-88) vs. 62 (3484) years, $p=0.01]$. Other demographics and clinical risk factors were similar between the groups. Previous medications and general characteristics of the study population are summarized in Table 1 . Serum creatinine $(\mathrm{p}=0.58)$, fasting glucose $(p=0.13)$, LDL- cholesterol $(p=0.16)$, HDL-cholesterol $(p=0.79)$, triglyceride $(p=0.40)$ and total cholesterol $(p=0.36)$ were not statistically different between inadequate and adequate CCD groups. Regarding hemogram parameters, hemoglobin $(\mathrm{p}=0.12)$, hematocrit $(\mathrm{p}=0.15)$ and platelet count $(\mathrm{p}=0.10)$ were similar in inadequate and adequate CCD groups. However, mean PDW values $[17.5 \%(10-23)$ vs. $12.4 \%$ (9.8-22), $\mathrm{p}<0.001]$ and mean PPR values $[0.07(0.03-0.19)$ and $0.05(0.03-0.23), p=0.01]$ of inadequate and adequate CCD groups were significantly different.

Laboratory data of the study population are given in Table 2. Of the 398 patients, 170 (64\%) had Rentrop grade 0,97 (36\%) had grade 1,67 (51\%) had grade 2 , and $64(49 \%)$ had grade 3 . The severity of the CAD according to number of vessels involved was not significantly differ-
TABLE2. Laboratory data of the study cohort

\begin{tabular}{|c|c|c|c|}
\hline & $\begin{array}{l}\text { Inadequate } \\
\text { CCD }(n=267)\end{array}$ & $\begin{array}{c}\text { Adequate } \\
\operatorname{CCD}(n=131)\end{array}$ & $\mathrm{p}$ \\
\hline & \multicolumn{2}{|c|}{ Median (Min.-Max.) } & \\
\hline Creatinine (mg/dl) & $0.9(0.5-2.1)$ & $0.9(0.4-2.3)$ & 0.58 \\
\hline $\begin{array}{l}\text { Fasting plasma } \\
\text { glucose (mg/dl) }\end{array}$ & $108(67-294)$ & $102(71-296)$ & 0.13 \\
\hline $\begin{array}{l}\text { LDL-cholesterol } \\
(\mathrm{mg} / \mathrm{dl})\end{array}$ & $109(38-235)$ & $112(44-225)$ & 0.16 \\
\hline $\begin{array}{l}\text { HDL-cholesterol } \\
(\mathrm{mg} / \mathrm{dl})\end{array}$ & $41(24-70)$ & $41(23-74)$ & 0.79 \\
\hline $\begin{array}{l}\text { Triglyceride } \\
(\mathrm{mg} / \mathrm{dl})\end{array}$ & $158(42-951)$ & $134(47-945)$ & 0.40 \\
\hline $\begin{array}{l}\text { Total cholesterol } \\
(\mathrm{mg} / \mathrm{dl})\end{array}$ & $174(113-298)$ & $183(85-294)$ & 0.36 \\
\hline Hematocrit (\%) & $42.4 \pm 5.7$ & $41.3 \pm 5.3$ & 0.15 \\
\hline PDW (\%) & $17.5(10-23)$ & $12.4(9.8-22)$ & $<0.001$ \\
\hline $\begin{array}{l}\text { Platelet counts } \\
\left(\mathrm{k} / \mathrm{mm}^{3}\right)\end{array}$ & $236(93-475)$ & $209(92-431)$ & 0.10 \\
\hline PPR (\%) & $\begin{array}{c}0.07(0.03-0.19) \\
\text { MEAN }\end{array}$ & $0.05(0.03-0.23)$ & 0.01 \\
\hline Hemoglobin (gr/dl) & $14 \pm 1.8$ & $14 \pm 1.7$ & 0.11 \\
\hline
\end{tabular}

CCD: Coronary collateral development; PDW: Palette distribution width; PPR: PDW to platelet ratio; SD: Standard deviation.

ent between inadequate cholesterol and adequate CCD (one vessel disease: $121(\% 45)$ vs. 57 (43\%), $\mathrm{p}=0.14$; two-vessel disease 96 (36\%) vs. 34 (26\%), $p=0.12$ and three-vessel disease $50(19 \%)$ vs. $40(30 \%), p=0.06)$

In multivariate analysis, age $(p=0.012,95 \%) C I$ for OR: $0.958(0.933-0.983)$ and $\mathrm{PDW}(\mathrm{p}<0.001,95 \% \mathrm{CI}$ for OR: $1.432(1.252-1.618)$ were found to be statistically significantly different inadequate CCD group compared to adequate CCD group (Table 3).

Pearson's correlation analysis revealed that PDW was significantly correlated with Rentrop score $(r=0.51$, $\mathrm{p}<0.001)$. ROC analysis revealed that a PPR value greater than 0.057 had $76 \%$ sensitivity and $51 \%$ specificity and a PDW greater than $16.2 \%$ had $80 \%$ sensitivity and $66 \%$ specificity in predicting inadequate CCD (Fig. 1).

\section{DISCUSSION}

Striking results of the present study showed that elevated PDW and PPR, indices of a simple routine hemogram 
TABLE 3. Multiple logistic regression analysis pointing independent predictors of the CCD

\begin{tabular}{lccc} 
& OR & $95 \% \mathrm{CI}$ & $\mathrm{p}$ \\
\hline BMI $\left(\mathrm{kg} / \mathrm{m}^{2}\right)$ & 0.982 & $(0.925-1.042)$ & 0.548 \\
Age & 0.958 & $(0.933-0.983)$ & 0.012 \\
Smoking & 0.342 & $(0.193-0.606)$ & 0.071 \\
PDW (\%) & 1.432 & $(1.252-1.618)$ & $<0.001$ \\
PPR & 0.712 & $(0.185-2.713)$ & 0.698 \\
\hline
\end{tabular}

CI: Confidence interval; OR: Odds ratio; PDW: Platelet distribution width; PPR: PDW to platelet ratio; BMI: Body mass index.

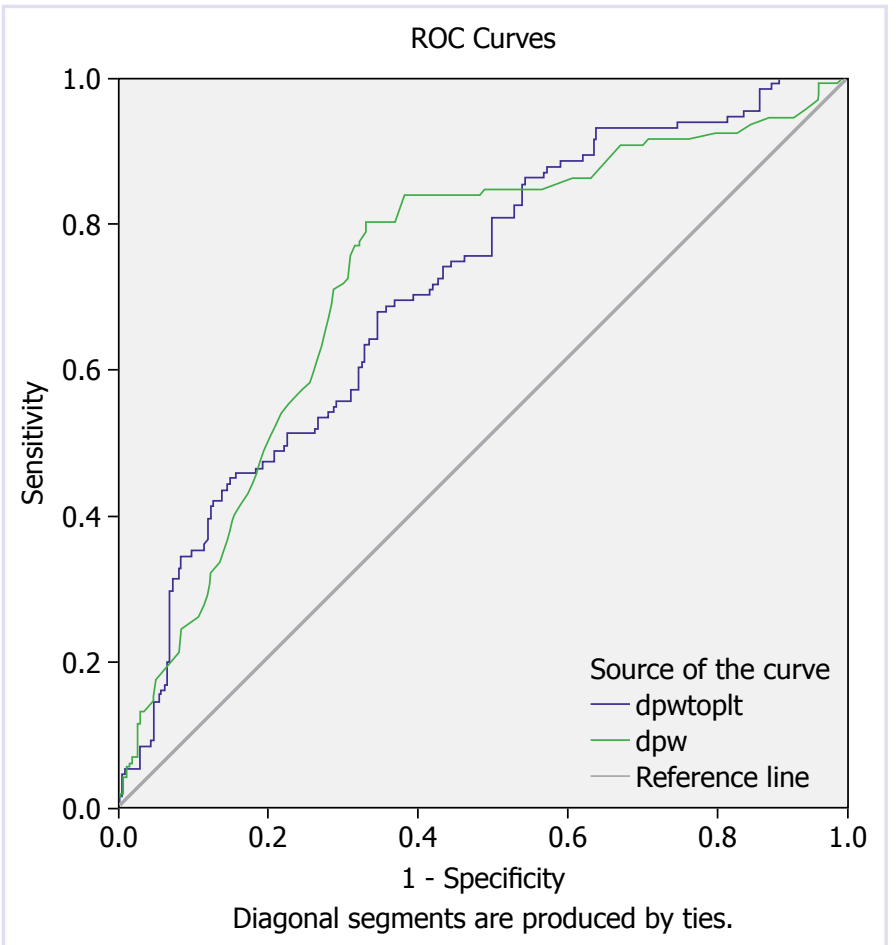

FIGURE 1. ROC curve analysis of PDW and PDW/P for prediction of inadequate. At the cut-off value of $>16.2 \%$, sensitivity and specificity of MPV were $80 \%$ and $66 \%$, respectively (AUC $=0.726,95 \% \mathrm{CI}, 0.673-0.780$ ). At the cut-off value of $>0.057$, sensitivity and specificity of PDW/P were $76 \%$ and $51 \%$, respectively (AUC $=0.708,95 \%$ CI, $0.655-$ 0.762). AUC: Area under the curve; CI: Confidence interval.

test could predict inadequate collateral development in chronic stable CAD. Limitation of infarct size, protection or improvement of left ventricular function and mortality in patients with CAD are associated with the presence of well-developed CCD $[2,14]$. Duration and/or the severity of coronary artery stenosis, endothelial dysfunction, endogenous mediators, hypertension, diabetes mellitus, dyslipidemia, smoking, and drugs are among factors that affect the development of CCD [15]. The development of angiogenesis is related to endogenous mediators and neurohumoral [16]. Furthermore, CCD could be affected by the inflammatory cells, such as monocytes, lymphocytes and platelets [17-22]. Platelets have a pivotal role in the development of atherosclerosis [17].

In regression analysis, we found that the PDW level is an independent predictor of CCD. Growth factors and cytokines in the atherosclerotic processes may interfere with platelet production in the bone marrow and cause higher values of PDW [23]. Therefore, the atherosclerotic process may be among underlying causes of elevated PDW in patients with CCD in the present study. Megakaryopoiesis and thrombopoiesis together determine the size of platelets. Cytokines, such as tumor necrosis factor- $\alpha$, interleukin- 1 , and interleukin- 6 , are expressed in the tumor microenvironment that is characterized by inflammation [23]. Interaction between these cytokines and platelet production in bone marrow may cause an early release of immature platelets into the bloodstream [24].

In a Japanese study, authors studied PPR in 275 breast cancer patients and found that PPR was a significant prognostic factor disease-free survival in that population [25]. In addition to nuclear grade and lymph node involvement, the authors suggested that PDW and PPR were also associated with inferior disease-free survival rates in a breast cancer study [25]. Diseases with the prominent amount of inflammation, such as acute appendicitis, have been associated with increased levels of PDW in the literature [26, 27]. Moreover, such an association has been shown in sepsis in a study from Turkey [28]. Conditions with low burden inflammatory processes, such as cancers, are also related to increased levels of PDW. Guo et al. reported that PDW was elevated in patients with hepatocellular carcinoma [29]. In another study, increased PDW was reported in diabetic subjects with diabetic nephropathy and diabetic retinopathy [30].

Association between the patency of saphenous vein grafts after coronary artery bypass graft operations has been analyzed and authors concluded that PDW of the subjects with occluded grafts was significantly higher than the PDW of patients with intact graft [9]. A study by Ozyurtlu et al. demonstrated that PDW was significantly elevated in subjects with coronary slow flow, an angiological phenomenon, compared to control subjects [31]. In accordance with the published 
studies, PDW was increased in patients with CAD and inadequate CCD.

In the light of the studies reported above, we shall speculate the reasons responsible for PDW and PPR elevation in subjects with inadequate CCD. Coronary artery disease may induce subclinical inflammation and drive some amount of inflammatory burden. Cytokines related to this inflammation may induce megakariopoesis in the bone marrow and stimulate the production of platelets resulting in increased platelet size variation. Therefore, PDW and PPR increase in patients with inadequate $\mathrm{CCD}$.

There are some limitations of the present study. First, the retrospective design of the study could make our results difficult to interpret. Second, a relatively small sample size of the study is another limitation. However, to our knowledge, this is the first study investigating the association between CCD and PDW and PPR.

\section{Conclusion}

The present study suggests that PDW and PPR may be associated with the severity of collateral development in chronic stable CAD. Simple hemogram parameters, PDW and PPR, could be predictors of coronary collateral development. Prospective larger cohort studies are needed to confirm our results.

Ethics Committee Approval: The Ethics Committee of Abant Izzet Baysal University Faculty of Medicine provided the ethics committee approval for this study (date: 04.12.2017, number: 68246970-903.99).

Conflict of Interest: No conflict of interest was declared by the authors.

Financial Disclosure: The authors declared that this study has received no financial support.

Authorship Contributions: Concept - IS, AKM; Design - IS, EE; Supervision - MC, YG; Materials - AKM, EE, MC; Data collection and/ or processing - MC, IS, GA; Analysis and/or interpretation - IS, AKM, YG; Writing - IS, YG, EE; Critical review - IS, GA, MC.

\section{REFERENCES}

1. Koerselman J, van der Graaf Y, de Jaegere PP, Grobbee DE. Coronary collaterals: an important and underexposed aspect of coronary artery disease. Circulation 2003;107:2507-511. [CrossRef]

2. Meier P, Gloekler S, Zbinden R, Beckh S, de Marchi SF, Zbinden S, et al. Beneficial effect of recruitable collaterals: a 10-year follow-up study in patients with stable coronary artery disease undergoing quantitative collateral measurements. Circulation 2007;116:975-83. [CrossRef]

3. Regieli JJ, Jukema JW, Nathoe HM, Zwinderman AH, Ng S, Grobbee $\mathrm{DE}$, et al. Coronary collaterals improve prognosis in patients with is- chemic heart disease. Int J Cardiol 2009;132:257-62. [CrossRef]

4. Nathoe HM, Koerselman J, Buskens E, van Dijk D, Stella PR, Plokker $\mathrm{TH}$, et al. Octopus Study Group. Determinants and prognostic significance of collaterals in patients undergoing coronary revascularization. Am J Cardiol 2006;98:31-5. [CrossRef]

5. Teunissen PF, Horrevoets AJ, van Royen N. The coronary collateral circulation: genetic and environmental determinants in experimental models and humans. J Mol Cell Cardiol 2012;52:897-904. [CrossRef]

6. Rief P, Raggam RB, Avian A, Hafner F, Sareban M, Wehrschuetz M, et al. Low mean platelet volume is associated with critical limb ischemia in peripheral arterial occlusive disease. Sci Rep 2018;8:6718, [CrossRef]

7. Hu CP, Du Y, Zhu Y, Shi C, Qin Z, Zhao YX. Platelet Distribution Width on Admission Predicts In-Stent Restenosis in Patients with Coronary Artery Disease and Type 2 Diabetes Mellitus Treated with Percutaneous Coronary Intervention. Chin Med J (Engl) 2018;131:757-63. [CrossRef]

8. Besli F, Ilter A, Gungoren F. The Link Between Mean Platelet Volume to Lymphocyte Ratio and Complexity of Coronary Artery Disease. Angiology 2018;69(4):358-59. [CrossRef]

9. Ege MR, Guray U, Guray Y, Acıkgoz S, Demirkan B. Platelet distribution width and saphenous vein disease in patients after CABG. Association with graft occlusion. Herz 2013;38:197-201. [CrossRef]

10. Vagdatli E, Gounari E, Lazaridou E, Katsibourlia E, Tsikopoulou F, Labrianou I. Platelet distribution width: a simple, practical and specific marker of activation of coagulation. Hippokratia 2010;14:28-32.

11. Matsuo K, Tang SH, Sharifi B, Rubin SA, Schreck R, Fagin JA. Growth factor production by human thyroid carcinoma cells: abundant expression of a platelet-derived growth factor-B-like protein by a human papillary carcinoma cell line. J Clin Endocrinol Metab 1993;77:996-1004.

12. Purbiya P, Golwala ZM, Manchanda A, Sreenivas V, Puliyel JM. Platelet Distribution Width to Platelet Count Ratio as an Index of Severity of Illness. Indian J Pediatr 2018;85:10-4. [CrossRef]

13. Rentrop KP, Thornton JC, Feit F, Van Buskirk M. Determinants and protective potential of coronary arterial collaterals as assessed by an angioplasty model. Am J Cardiol 1988;61:677-84. [CrossRef]

14. Habib GB, Heibig J, Forman SA, Brown BG, Roberts R, Terrin ML, et al. Influence of coronary collateral vessels on myocardial infarct size in humans. Results of phase I thrombolysis in myocardial infarction (TIMI) trial. The TIMI Investigators. Circulation 1991;83:739-46.

15. Werner GS, Ferrari M, Heinke S, Kuethe F, Surber R, Richartz BM, et al. Angiographic assessment of collateral connections in comparison with invasively determined collateral function in chronic coronary occlusions. Circulation 2003; 107:1972-7. [CrossRef]

16. Imhof BA, Aurrand-Lions M. Angiogenesis and inflammation face off. Nat Med 2006;12:171-2. [CrossRef]

17. Pekdemir H, Polat G, Cin VG, Camsari A, Cicek D, Akkus MN, et al. Elevated plasma endothelin-1 levels in coronary sinus during rapid right atrial pacing in patients with slow coronary flow. Int J Cardiol 2004;97:35-41. [CrossRef]

18. Gok M, Kundi H, Kiziltunc E, Topcuoglu C, Ornek E. Endocan Levels and Coronary Collateral Circulation in Stable Angina Pectoris: A Pilot Study. Angiology 2018;69:43-8. [CrossRef]

19. Açar G, Kalkan ME, Avci A, Alizade E, Tabakci MM, Toprak C, et al. The relation of platelet-lymphocyte ratio and coronary collateral circulation in patients with stable angina pectoris and chronic total occlusion. Clin Appl Thromb Hemost 2015;21:462-8. [CrossRef]

20. Kurtul A, Yarlioglues M, Murat SN, Ergun G, Duran M, Kasapkara $\mathrm{HA}$, et al. Usefulness of the platelet-to-lymphocyte ratio in predicting angiographic reflow after primary percutaneous coronary intervention 
in patients with acute ST-segment elevation myocardial infarction. Am J Cardiol 2014;114:342-7. [CrossRef]

21. Hotchkiss RS, Karl IE. The pathophysiology and treatment of sepsis. N Engl J Med 2003;348:138-50. [CrossRef]

22. Duffy BK, Gurm HS, Rajagopal V, Gupta R, Ellis SG, Bhatt DL. Usefulness of an elevated neutrophil to lymphocyte ratio in predicting longterm mortality after percutaneous coronary intervention. Am J Cardiol 2006;97:993-6. [CrossRef]

23. Kayacan O, Karnak D, Beder S, Güllü E, Tutkak H, Senler FC, et al. Impact of TNF-alpha and IL-6 levels on development of cachexia in newly diagnosed NSCLC patients. Am J Clin Oncol 2006;29:328-35.

24. Kaushansky K. Growth factors and hematopoietic cell fate. A new feature: controversies in hematology. Blood 1998;92:345-4. [CrossRef]

25. Takeuchi H, Abe M, Takumi Y, Hashimoto T, Kobayashi R, Osoegawa $\mathrm{A}$, et al. The prognostic impact of the platelet distribution width-to-platelet count ratio in patients with breast cancer. PLoS One 2017;12:e0189166. [CrossRef]

26. Aydogan A, Akkucuk S, Arica S, Motor S, Karakus A, Ozkan OV, et al. The Analysis of Mean Platelet Volume and Platelet Distribution Width
Levels in Appendicitis. Indian J Surg 2015;77:495-500. [CrossRef]

27. Dinc B, Oskay A, Dinc SE, Bas B, Tekin S. New parameter in diagnosis of acute appendicitis: platelet distribution width. World J Gastroenterol 2015;21:1821-6. [CrossRef]

28. Orak M, Karakoç Y, Ustundag M, Yildirim Y, Celen MK, Güloglu C. An investigation of the effects of the mean platelet volume, platelet distribution width, platelet/lymphocyte ratio, and platelet counts on mortality in patents with sepsis who applied to the emergency department. Niger J Clin Pract 2018;21:667-71. [CrossRef]

29. Guo F, Zhu X, Qin X. Platelet Distribution Width in Hepatocellular Carcinoma. Med Sci Monit 2018;24:2518-23. [CrossRef]

30. Liu J, Liu X, Li Y, Quan J, Wei S, An S, et al. The association of neutrophil to lymphocyte ratio, mean platelet volume, and platelet distribution width with diabetic retinopathy and nephropathy: a meta-analysis. Biosci Rep 2018;38:BSR20180172. [CrossRef]

31. Ozyurtlu F, Yavuz V, Cetin N, Acet H, Ayhan E, Isik T. The association between coronary slow flow and platelet distribution width among patients with stable angina pectoris. Postepy Kardiol Interwencyjnej 2014;10:161-5. [CrossRef] 